\title{
OPPORTUNITIES FOR STRATEGIC DEVELOPMENT OF SMALL BUSINESS IN BULGARIA
}

\author{
Venelin Terziev $^{1 \star}$, Nikolay Nichev ${ }^{2}$, Evgeniy Stoyanov ${ }^{3}$, Marin Georgiev ${ }^{4}$, Plamen \\ Bogdanov $^{5}$ \\ ${ }^{1}$ Corresponding Member of the Russian Academy of Natural History, Moscow, Russia Professor, \\ Ph.D., D.Sc. (National Security), D.Sc. (Ec.), University of Rousse, Rousse, Bulgaria; National \\ Military University, Veliko Tarnovo, Bulgaria; University of Telecommunications and Post, Sofia, \\ Bulgaria, terziev@skmat.com \\ ${ }^{2}$ Colonel Associate Professor, Ph.D., National Military University, Veliko Tarnovo, Bulgaria, \\ nicheff@gmail.com \\ ${ }^{3}$ Professor, Ph.D., D.Sc. (Ec.), Agricultural University, Plovdiv, Bulgaria, evg_stojanov@abv.bg \\ ${ }^{4}$ National Military University, Veliko Tarnovo, Bulgaria, clementon@abv.bg \\ ${ }^{5}$ Brigadier General, Ph.D., National Military University, Veliko Tarnovo, Bulgaria, vrousse@abv.bg \\ ${ }^{*}$ Corresponding author
}

\begin{abstract}
The article examines the relationship between the socio-economic categories "strategy" and "small business", which are the key factors for the success of the economic system in Bulgaria. The aim of the project is to reveal and prove the prospects for improvement of the small business through the rational application of strategies. The purposeful decomposition of the goal is related to tasks revealing the evolution of the "strategy" category and finding opportunities to interact with the processes that drive small businesses. The accumulation of evidence is based on a principle basis, while the registered trends based on analyses are synthesized. On this basis, the expose is committed to substantiating the main thesis of development, which states that the application of strategies and strategic thinking in the development of the small business phenomenon is an important factor for its stable development and appropriate improvement.
\end{abstract}

Keywords: strategy, model, small business.

\section{INTRODUCTION}

The content definition of the strategy is the subject of management theory. It is known that the etiological root of term strategy ("strategia") is related to Greek. Its origin is associated with the ancient Greek poleis, and its literal translation is - a skill and a set of scientific knowledge of „warfare”. There are many definitions of 
the essence of the studied term in the scientific literature, many of which are similar to each other. Defining the term "strategy" and its study have a key role in clarifying the issues under consideration.

Systematic study of economic strategy dates back relatively soon. Most of the corporate organizations resulting from successful mergers have experienced significant prosperity through strategies based on both experiences and intuition, as well as in-depth analysis. With the complicating of economic activity, the opportunities for progress become dependent on the introduction of strategies based on realistic interpretation and objectivity for the established market positions of the organizations and the opportunities for development.

\section{DEVELOPMENT OF THE ECONOMIC CATEGORY "STRATEGY"}

In a modern economic sense, the strategy is characterized as a set of theories that form a certain management doctrine, with the development of tactical-descriptive plans (Trifonova, 2005). The variety of adequate definitions of the concept under consideration does not obstruct the process of improving its content, but at the same time it tracks the evolutionary development of the idea on the basis of which it was formed.

In the 1960s, it was argued that the strategy was to define the main long-term goals and tasks of the organization and the adoption of actions, allocation of the resources needed to meet these objectives (Chandler, 1965, p. 13). It is developed in the context of the Decision theory associated with the achievement of objectives by choosing a combination of available resources.

The next stage in development is related to the representatives of the Game Theory (Coates, 1978, p.143), according to whom the strategy is a specific use of resource availability under the control of the decision maker, whose preference is expressed in the selection of one of the available strategies (Miller, D., M. Starr, 1985 , p.157). At this stage of the development of the management thought, Bulgarian authors also emphasize the use of the material and labour resources as a major factor for the implementation of the organizational strategy. An important aspect of the economic strategy is the introduction of the requirement to study the behaviour of corporate counterparts and competitors in the light of defined and implemented initiatives for the strategic development of organizations (Dinev M., 1985, p. 200).

In the 70 s of the twentieth century the strategic management concept unfolds a discussion on the role of strategic planning to clarify whether it is content or is one of the components of strategic management. The substantial transformation that has been recorded at this stage in the content of "corporate planning" has been shaped by the emphasis placed on its long-term character, given its strategic aspect in order to be conceptualized as an essential part of strategic management. At this stage, corporate planning records the need for a rational plan covering all aspects of economic activity (Trifonov T., 2005). At the same time, strategic planning addresses the plan by focusing on its long-term and targeted nature (including the financial plan but excluding its detailed short-term alternative in the form of accounting budgeting). Strategic management focuses on the overall structural reorganization of organizational activity with the direction of adapting it optimally to environmental changes.

In the development of strategic management in the late 1970s, Ansoff's theoretical developments were particularly influential. Following the logic of the thesis that strategic decisions are related primarily to external rather than internal problems of the organization and especially to the choice of production nomenclature and the markets for its realization, he continues and develops it (Ansoff, 1965, p. 9). Considering each solution as a resultant variable concretized under the influence of input from the outside environment, in the form of signals of varying intensity and significance, Ansoff and his school develop a "Methodology for the use of weak signals" (Ansoff, 1984a, p.430-471).

In the analysis of the proposed methodology, the factor value of the input information is raised. The semantic emphasis is placed on weak signals from the external environment as the most important source for indicating emerging trends that predetermine the planning of responses by the organization in question. Response dynamics and a wide choice of decision options diagnose readiness and provoke successful strategic development in the conditions of weak signals.

In the process of exhibiting the theoretical development of Ansoff, along with the proven innovations that provide the motivation for seeking motivations for improvement in the development of the strategic themes, some weaknesses can be noted. First of all, the implementation of control in strategy modelling is ignored. It is formed as a result of the impact of weak signals from the external environment. The role of control is diminished; it is formalized and applies only to incoming information. The observed deformation of the control function causes a deficit both on the implementation of the strategic process and on the mechanism of its updating. 
In the 1980s, the strategic management concept based on the strategic analysis thesis gradually emerged. Management theory specialists at this stage expand the scope of strategic analysis by including all aspects of organizational environmental relations. This determines a far greater variety of management objects that can be categorized and qualified as the subject of strategic research.

The characteristics of the economic strategy are objectively defined by setting its target content, focusing on the role of the production-financial factors, emphasizing the need to acquire competitive advantages of the organization. The strategy at this stage is considered as the basic framework for cost-effective, resourceefficient utilization, specifying the procedures for implementation of organizational, business goals (Hofer, Schendel, 1978, p. 25). It is stated that the strategy provides for the possibility of a competitive advantage (Porter, 1985, p.26). The formulated strategic decisions are differentiated from the position of the specificity of the organization under consideration and its sectoral situation - factors that influence the applied methods used in the process of making the specific decisions.

The strategy has, above all, the characteristics of a specific expression of the particular organization, clearly defining that it is a selective, forward-looking activity that is sustainable over time, focusing on certain priorities (Mintzberg, Ahlstrand, Lampel, 1997, p. 23-45) and organizational characteristics. From the content point of view, the strategy is a long-term plan for permanent monitoring of the implementation of the use of the aggregate of internal and external resource potential in the hierarchical management structure for implementation of the organizational goals. Formal and content requirements are formulated to differentiate the strategy so that it is clearly defined to qualify as a logical unity of management interpretations and solutions for specific purposes and specific policies for their implementation, established scope of regulated activity and expected effects of its implementation (Andrews, 1980, p. 6).

An important role in the development of management thinking about strategic management has the Minzburg School. For, this school, in the full and specific meaning, we can apply the definition „alternative” in terms of evolution in the development of the strategy topic. Over time, the definitions of the strategy in the economic sphere are specified while preserving its target character, but the focus of the material, resource factors is shifted on the intangible ones, and their priority is reinforced (Mintzberg, 1973a, p. 91). This qualitative jump registers a tendency for a change in the strategic process, with the corresponding conceptual weight of planning shifting to system analysis. In terms of content, the 'behavioural model' addendum is also relevant to the definition of the strategy.

Reconciliation in the process of making and implementing a strategy of several characteristics, such as an action plan, a pattern of behaviour, a means of achieving and maintaining a competitive position, proves in addition to content and formal improvement (Mintzberg, 1973b, p. 47). Emphasizing the process of modelling and implementing a specific behavioural model and introducing adjustments to it in order to fully coordinate the potential of the behavioral model and the desired strategic outcome proves the irreversibility of the process of introducing the Feedback Mechanism into the strategic process. Strengthening the role of feedback in the strategic process traces the possibilities for development and improvement both in content and in functional aspect.

By analysing the turbulent processes of dynamic economic reality, by comparing the importance of theoretical developments to the development of management thought, proving the increasing impact of their practical applicability, it can be assumed that Ansof's main contribution is to focus attention on the issues of implementation of the strategy, although this importance in some areas is over-exposed (Ansoff, 1984b, p. 33-36). As the most significant contribution of the Mutzburg School, one can note the motivated shortening of the implementation cycle of strategies and the introduction and demonstration of the growing role of strategic control with feedback (Mintzberg, 1979, p. 34-43).

As a method of corporate governance, the strategy was initially implemented in the field of organizational activity planning (Stoyanov, 2013, p. 141). In the period 1970-1990, strategic planning has become a leading field in theoretical and managementthought in the most advanced economies. At present, strategic management is sufficiently detailed in the methodological management theory. It is seen as the unity of formulated, managerial decisions and action taken in relation to the definition and implementation of strategies to achieve certain, organizational goals, organized as a process through which long-term, sustainable development is achieved (Mihnev, 1999, p. 19). A certain group of Bulgarian authors engage the content of corporate, strategic management and the inevitable inclusion of operational / situational / management based on the adherence of the organization to a specific strategy. It is natural that the strategic management is in priority interconnected with the process of developing strategic and long-term solutions (Pamukchiev, 2002, p. 189). 
As elements of strategic management are defined: vision design, mission definition, goal specification, strategy implementation and evaluation of registered results.

\section{BASIC STRATEGIC LINES IN THE DEVELOPMENT OF SMALL BUSINESS}

It is indisputable that organizations work as they purposefully carry out their activities, implementing a specific, policy and strategic line. Successful, organizational development is an actual result of the implementation of plans formed in the consolidation of strategic and operational management. However, in the consolidation process, one important point is noticeable - a significant discrepancy between the planning values set by the strategic and operational planning management objectives. This significant fact predetermines the definition and differentiation of the notions of "strategic planning" and "strategic control” (Gould, Campbell, 1995, p. 33-34).

Especially interesting is that the same fact is forgotten by a number of managers working in the small business, i.e. they probably forget that an effective method of control is "strategic planning" (Daft, 2005, p. 787). Because in most cases the business they manage consists of one or more operations, they ignore the opportunity to fit into a strategy the stock management, the delivery of parts or the presence of seasonal market fluctuations. In this sense, it may be of prime importance for small businesses to devote themselves to the operational strategy.

The underlying understanding of an organizational strategy is based on the ability to recognize the importance of operations in organizational success, with responsibility being associated with the involvement of managers in the development of a strategic plan (Stoyanov, 2005, p. 41).

In a more specific context, the goal of this strategic model is to link the strategy to decision-making at the operations level, i.e. to build a compact framework for specific decision-making (Andronov, Aleksandrova, 2005 , p. 18). The structure of the framework covers separate policies and fixed results, which are missionoriented and focused on "differentiating competitiveness".

The analysis of multiple operational strategies provides an opportunity to find out that their running and practical implementation takes the form of a multi-stage process.

The comprehensive review of the operational strategy makes it possible to identify two development paths that greatly justify the strategic thinking and organizational behaviour of small business representatives.

One line is the optimization of the movement and improvement of material flows, a process that presupposes efficient transformation of materials and raw materials into an end product, regardless of form.

The other line, gaining ever greater significance, is the effective improvement achieved in seeking competitiveness.

The first strategic line, i.e. the process of streamlining commodity flows in the manufacturing process, can in particular be described as logistics, in particular the so-called logistical coordination, i.e. in this productionfunctional compilation, the image of the "complex" organizational function can be recognized.

In essence, this concept is aimed at improving the management of the logistics base, i.e. logistics becomes an organizational and economic tool for coordinating the purposeful movement of commodity-material flows, and it is on this basis that the management process improves the activities of the modern enterprise.

In detail, according to the subject of small business activity, several basic types of chains are distinguished, characterizing the movement of material flows in the production process. In a detailed plan, two groups are defined - production/delivery and transport/service (Galloway, 1994, p. 21-23).

Despite the existence of a mechanism optimizing the flow of material flows and increasing the efficiency in the production process from the presented schemes it can be seen that the process of improvement continues to evolve. In favour of logistics, it can be said that from functional optimization, its focus moves in a different direction, taking the place of one of the leading concepts that predetermines the optimal efficiency of management.

In this line of thought, the other strategy defining the success of small businesses in relation to the level of competitiveness develops too. Interesting and illustrative is the fact that the business world, and in particular that part of small business, proves that conceptually, rising competitiveness can also be seen as a result of efficient logistics.

Market presence determines the need for each market participant to improve the level of competitiveness. The competitive advantages of non-scale organizations are set at the stage of goal-setting and strategy structuring. 
Significant shocks in the global economic system create conditions for remodelling market behaviour. The retreat of mass marketing and its replacement by acustomized one is evidence that manufacturers are carefully studying the changes in their customers' needs and thus making a step ahead of the competition.

The psychology of this communication makes the client-customer relationship a peer-to-peer partnership and an indispensable source of ideas for organizational improvement and optimization of market behaviour. The act of reaching consumer loyalty can be seen as a result of, on the one hand, ensuring the quality of the goods and services offered and, on the other hand, the quality of the business processes themselves (Stoyanov, 2014, p. 81).

The philosophy of quality development is developing in the concept of Total Quality Management (TMQ) and in its follow-up concept of Total Quality Control (TQC) (Gludkin, 1999, p. 19). One of the main methods for optimizing the quality management system is the commented in the previous chapter, "The Deming Cycle”. On the occasion of its application, it is argued that securing competitiveness can be ensured if the model under consideration is a standard for all levels of activity (Deming, 2006, p. 13).

Looking at the work of small business and the thorough analysis of the results achieved, it proves that in certain stages and in particular business processes this model may prove to be low effective, taking into account the resource constraints regarding: human, material, financial, information resources and planned improvements cannot be fully implemented. In small business, management is often intuitive, and a small circle of managers make decisions on a wide range of issues of a different nature. It is precisely in such situations that the process of refinement can stumble or an irreconcilable contradiction between the need for change and the limited organizational capacity can be reached. The experience of many small businesses proves that under such circumstances, the possibility of gradual optimization of processes is increasingly ignored and recourse is being made to the ready-made process decisions applied by leaders in the specific field, i.e. best practice or benchmarking are applied.

Despite the apparent elementary nature of the process of translation of the chosen standard this method poses risks too, because adapting good practice and achieving optimal efficiency are achievable only by observing a number of factors of different nature - local legislation, specificity of activity, national mentality, traditions, etc. Quite a lot of attempts to apply benchmarking have the impression of a negative effect because the improvement of certain activities such as market analysis, financial analysis, audit, etc. generates substantial costs for the organization itself. Along with this, additional staff training, additional technical solutions, or the introduction of more specialized software make pointless to include another good practice in small business. In such situations, efficiency can be achieved by attracting an outside organization specialized in the specific area, i.e. the solution is popular as outsourcing.

Although the solution is known for a long time, opinions about it are in a sense quite controversial. Since the late 1990s, it has been argued that outsourcing of business processes is less effective than outsourcing of technologies. Analysts believe that this trend is more typical for small businesses where resource problems are associated with both their application performance and their „permanent insufficiency”.

Critical review of outsourcing implementation in small businesses has the potential to detect both positive and negative effects. The main arguments in favour of outsourcing are associated with the savings of funds and the creation of an opportunity to increase the concentration of limited and insufficient own resources on the core business and related operations. As a negative effect of outsourcing, it may be mentioned that the presence of external specialists or personal formations is difficult to integrate into organizational goals, and even less often practice the organizational culture or conform to the imposed pattern of behaviour.

\section{SUMMARY AND CONCLUSION}

The analysis of trends that have a significant impact on the development of small businesses make it possible to focus attention on building a competitive advantage on the basis of these strategies, while taking into account the slowly-optimizing business processes and the limited resources. In this sense, scientists and consultants work on creating models that provide solutions for good efficiency and the best possible results. For such a successful experience can be mentioned the "Three Step Strategic Model".

The generic conclusion that can be drawn in the analysis of the application of small business strategies begins with the fact that the truly limited scale directs the focus of attention to the operational level and in this respect some of the strategies are associated with technology and quality. Exploring strategies as a big and long-term plan is becoming more and more difficult for an objective implementation, and for this reason its application is spoken with certain conditionality, i.e. the application is possible and it brings benefits only to economic actors with the features of small multiprofile organizations. In this sense, it is desirable to speak of strategic thinking in small business - globally, and more specifically in Bulgaria, because it is an alternative 
for active control and an objective opportunity to reveal the strategic organizational potential and its successful improvement.

\section{REFERENCES LIST}

Chandler, A., (1965) Strategy and Structure, Cambridge, Mass: MIT Press.

Coates, C., (1978) Investment Strategy, McGraw-Hill.

Hofer, C., D., Schendel, (1978) Strategy Formulation: Analytical Concepts, NY.

Miller, D., M. Starr, (1985) The Structure of Human Decision, Prentice Hall, 1967.

Stoyanov E.N., (2005) One Successful Strategic Control Idea, Anthey-TN, Burgas.

Andronov E., M. Aleksandrova, (2005) Operations Management, S., Stopanstvo.

Stoyanov E.N., (2014) Small Business Organization, Analysis and Evaluation, Libra Scorp, Burgas.

Stoyanov E.N., (2013) Theory of Financial and Economic Analysis, Libra Scorp, Burgas.

Deming E., (2006) The New Economics, MIT Press, Cambridge, Massachusetts, 2nd Ed.

Mihnev G., (1999) Strategic Management of Agricultural Farms, Stopanstvo, S.

Mintzberg. H., (1973a) The Nature of Managerial Work, NY; Harper \& Row.

Mintzberg, H., (1973b) Strategy-Making in Three Modes, California MR, Winter.

Mintzberg, H., (1979) The Structure of Organizations. Englewood Cliffs, NJ; Prentice-Hall.

Mintzberg, H., B. Ahlstrand, J. Lampel, (1997) Strategy safari. A Guided Tour through the Wilds of Strategic Management.L.etc.

Ansoff, I., (1965) Corporate Strategy, NY.

Ansoff, I., (1984a) Implanting Strategic Management, Prentice/Hall I.; N.J.

Ansoff, I., (1984b) Implanting Strategic Management, Prentice/Hall I.; N.J.

Andrews, K., (1980) The Concept of Corporate Strategy, 2-nd ed., NY.

Galloway L., (1994) Principles of Operations Management, London, ITBP.

Dinev, M., (1985) Social Control and the Work Team, Profizdat.

Porter, M., (1985) Competitive Strategy, Free Press, NY.

Pamukchiev M., (2002) Principles of Management, ABC Technika, S.

Gould, M., Campbell E., (1995) Strategies and Styles: The Role of the Center in Corporate Governance, M., Peter.

Gludkin O., (1999) General Quality Management, M., Radio and Communication.

Daft R., (2005) Vanderbilt University, Management, 6th edition, Thomson.

Trifonova S., (2005) Strategies for Development of Electronic Financial Services in Bulgaria, UNWE, Scientific works

Trifonov T., (2005) Strategic Analysis as a Modern Prerequisite for Improvement of the Accounting Value Study, UNWE Scientific works. 